\title{
Testing the Confluence Model of the Association Between Pornography Use and Male Sexual Aggression: A Longitudinal Assessment in Two Independent Adolescent Samples from Croatia
}

Kohut, Taylor; Landripet, Ivan; Štulhofer, Aleksandar

Source / Izvornik: Archives of Sexual Behavior, 2020, -

Journal article, Accepted version

Rad u časopisu, Završna verzija rukopisa prihvaćena za objavljivanje (postprint)

https://doi.org/10.1007/s10508-020-01824-6

Permanent link / Trajna poveznica: https://urn.nsk.hr/urn:nbn:hr:131:552622

Rights / Prava: In copyright/Zaštićeno autorskim pravom.

Download date / Datum preuzimanja: 2023-04-26

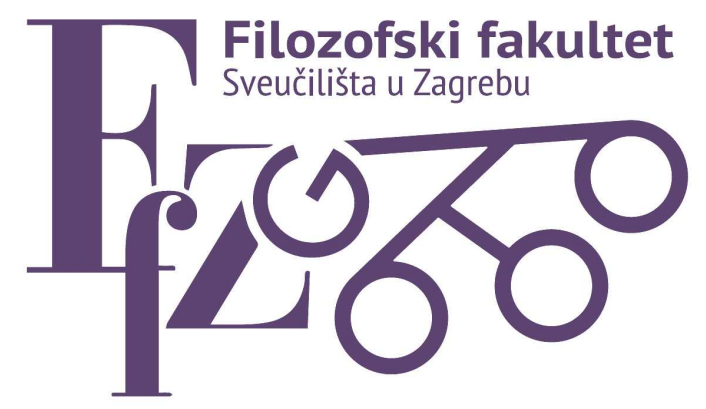

Repository / Repozitorij:

ODRAZ - open repository of the University of Zagreb

Faculty of Humanities and Social Sciences
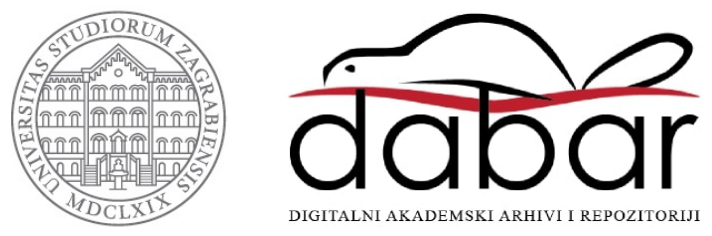
Testing the Confluence Model of the Association Between Pornography Use and Male Sexual Aggression: A Longitudinal Assessment in Two Independent Adolescent Samples from Croatia

Taylor Kohut ${ }^{\mathrm{a}, \mathrm{b}}$, Ivan Landripet ${ }^{\mathrm{a}}$, \& Aleksandar Štulhofer ${ }^{\mathrm{a}}$

Affiliations: a Department. of Sociology, Faculty of Humanities and Social Sciences, University of Zagreb, Zagreb, Croatia; ${ }^{b}$ Department of Psychology, Faculty of Social Science, University of Western Ontario, London, Canada.

Address for Correspondence: Taylor Kohut, PhD, tkohut@,uwo.ca, 7430 Social Science Centre, University of Western Ontario, 1151 Richmond St, London, ON, Canada, N6A 3K7

Funding Source: This work was supported by the Croatian Science foundation [grant \#9221 awarded to the last author] and the University of Zagreb. 


\begin{abstract}
ABTRACT
According to confluence model theorizing, pornography use contributes to sexual violence, but only among men who are predisposed to sexual aggression. Support for this assertion is limited to cross-sectional research, which cannot speak to the temporal ordering of assumed causes and consequences. To address this issue, we employed generalized linear mixed modeling to determine if hostile masculinity, impersonal sexuality, and pornography use, and their interactions, predicted change in the odds of subsequently reported sexual aggression in two independent panel samples of male Croatian adolescents $\left(N_{1}=936\right.$ with 2,808 observations; $N_{2}=$ 743 with 2,972 observations). While we observed the link between hostile masculinity and selfreported sexual aggression in both panels, we found no evidence that impersonal sexuality and pornography use increased the odds of subsequently reporting sexual aggression-regardless of participants' predisposed risk. This study's findings are difficult to reconcile with the view that pornography use plays a causal role in male sexual violence.
\end{abstract}

Keywords: Pornography; sexual aggression; confluence model; adolescence 
Testing the Confluence Model of the Association between Pornography Use and Male Sexual Aggression: A Longitudinal Assessment in Two Independent Adolescent Samples from Croatia

\section{INTRODUCTION}

In recent years, a deluge of personal disclosures of sexual victimization (i.e., \#MeToo) and high-profile allegations of sexual misconduct, harassment, and assault have revitalized contemporary discussions of sexual aggression. As these examples make clear, sexual aggression can inflict a range of physical (i.e., physical injury, sexual/reproductive health consequences, death), mental (i.e., depression, anxiety, post-traumatic stress disorder, suicidality, etc.), and social harms (i.e., stigmatization, ostracism, honor killings, etc.) (Krug et al., 2002). It has been estimated that more than 430,000 sexual assaults occurred in the United States in 2015 (Truman \& Morgan, 2018), with the burden of victimization generally falling predominantly on women and girls (Snyder, 2000). In 2015, around 215,000 violent sexual offenses were recorded by the police in the European Union, with more than 8 in 10 victims being girls and women and $99 \%$ of the perpetrators being males (Eurostat, 2017). A recent multinational perpetration/victimization survey conducted across 10 European countries found that approximately one third $(32.2 \%)$ of young adult women in these countries were victims of sexual aggression (Krahé et al., 2015).

Sexual violence also occurs among adolescents. In fact, the U.S. Department of Justice has estimated that girls between the ages of 16-19 are four times more likely to be victims of sexual aggression than the general public (Greenfeld, 1997). Acknowledging difficulties with integrating such findings, Bonino et al. (2006) have estimated that approximately $15 \%$ of adolescent girls and $10 \%$ of adolescent boys are victims of "unwanted sexual attention" or sexual violence. Importantly, adolescents may also be perpetrators of sexual aggression; a large national 
sample of American teens found that 5\% of adolescents reported engaging in sexual aggression (e.g., unwanted kissing, touching, or sexual behavior) over a three year period (Ybarra et al., 2011).

\section{Sexual Aggression and Pornography}

There have been longstanding concerns that pornography use contributes to sexual aggression (Commission on Obscenity and Pornography, 1971), and while conclusions continue to be contested (cf. Ferguson \& Hartley, 2009, 2020; Fisher et al., 2013; Kingston et al., 2009), a growing body of evidence connects pornography use to self-reports of sexual aggression among adolescents. Cross-sectional and longitudinal research in the U.S., Norway, Italy, and Taiwan all indicate that adolescents who use more pornography report engaging in more sexual harassment and aggression (Bonino et al., 2006; Brown \& L'Engle, 2009; Chang et al., 2016; Kennair \& Bendixen, 2012; Ybarra et al., 2011; Ybarra \& Thompson, 2018). Indeed, meta-analytic work has also found that the association between pornography use and sexual violence did not differ between adolescents and adults (Wright et al., 2016).

The confluence model of sexual aggression is an influential theoretical explanation for the role that pornography use plays in male sexual violence directed towards women (Malamuth, 2018; Malamuth \& Hald, 2017). Of particular importance, it argues that not all male users are equally vulnerable to this influence. According to the confluence model, sexual aggression is the product of the interactive confluence of proximate risk factors of sexual aggression-primarily the constructs of hostile masculinity, impersonal sexuality, and pornography use. In this approach, hostile masculinity has been described as a "narcissistic, insecure, defensive, hypersensitive, and hostile-distrustful orientation" (Malamuth \& Hald, 2017, p. 54) towards women accompanied by the sexual desire to control and dominate women. In contrast, 
impersonal sexuality is said to be a "promiscuous detached orientation towards sexual relations" (Malamuth \& Hald, 2017, p. 54), which appears to be conceptually—if not operationallysimilar to Simpson and Gangestad's (1991) conceptualization of sociosexuality. With respect to pornography use, the confluence model "contends that for a small subgroup of users, who already score high on other known risk factors of sexually [sic] aggression, high pornography consumption may add 'fuel to the fire' and increase the risk of sexually aggressive attitudes and behaviors...by aiding the creation, reinforcement, or priming of (pre-existing) sexually aggressive attitudes, cognitions, and emotions” (Hald \& Malamuth, 2015, p. 100).

Although the role of pornography use has not received as much research attention as other aspects of the confluence model, available evidence supports the view that pornography use may be a risk factor for sexual aggression among high-risk men. Specifically, cross-sectional research has indicated that pornography use is correlated with self-reported sexual aggression (Baer et al., 2015; Malamuth et al., 2000) and attitudes supportive of sexual aggression (Malamuth et al., 2012), but only, or primarily, among men who are predisposed to sexual aggression. Recent experimental work inspired by the confluence model has also found that exposure to pornography increased attitudes supporting violence towards women, but only among men who were low in agreeableness (Hald \& Malamuth, 2015)—a distal risk factor that is thought to be mediated by hostile masculinity.

Malamuth's conceptualization of the confluence model is not without criticism. At present, the confluence model's assertion that pornography plays a causal role in sexual aggression remains unverified. The available evidence concerning the interactive contributions of pornography use, hostile masculinity, and impersonal sexuality comes exclusively from crosssectional research. The sole experimental study in this area did not examine interactions between 
hostile masculinity, impersonal sexuality, and pornography exposure (Hald \& Malamuth, 2015). It focused, instead, on more distal predictors of sexual aggression. For obvious ethical reasons, it also examined pornography-induced changes in attitudes toward sexual aggression rather than self-reported acts of sexual aggression. Although there is an older longitudinal study that tested some components of the confluence model (e.g., Malamuth et al., 1995), it predates the conceptual inclusion of pornography use as one of the key risk factors for sexual aggression (Malamuth et al., 2000). Thus, longitudinal testing of the confluence model remains an imperative.

The asserted causal relationship between pornography use and sexual aggression in the confluence model has also been challenged for failing to account for potential confounds (Baer et al., 2015). High sexual interest (or "sexual drive," as often termed in the confluence model literature) may be one such factor. It is independent of the construct of impersonal sexuality (Malamuth et al., 1995), but correlated with pornography use (Baer et al., 2015), self-reported sexual aggression (Malamuth et al., 1995), and paraphilic sexual interests (Dawson et al., 2014). If sexual interest is an important confound of the association between pornography use and sexual aggression, then pubertal development which has been linked to sexual interest (Fortenberry, 2013) and pornography use among adolescents (Beyens et al., 2015) may be a further confound that is worth considering. Other potential confounding variables that have been linked to both pornography use and sexual aggression (or sexual harassment) include sensation seeking (Beyens et al., 2015; Brown \& L’Engle, 2009; Lalumière \& Quinsey, 1996), impulsiveness (Brown \& L'Engle, 2009; Carvalho \& Nobre, 2013; Hardy et al., 2013), and social desirability (Rasmussen et al., 2018; Tan \& Grace, 2008). It is conceivable that each of these variables may independently causally influence pornography use and sexual aggression, or 
self-reports of such behaviors, contributing to spurious correlations between these two constructs.

Understanding the actual causal effects of pornography use with correlational research requires the careful consideration of a range of plausible causal models (Kohut et al., 2020). Specifically, in this case, confluence model theorizing asserts that it is exposure to sexual media content itself, rather than other associated behaviors (e.g., masturbation) and individual predispositions (e.g., sex-drive, sensation seeking, impulsiveness, and social desirability, etc.) that is responsible for reinforcing and activating relevant rape-supportive cognitions, affect, and attitudes. Failing to control for constructs that jointly influence pornography use and sexual aggression may substantially affect estimations of the activating effects of pornography use on sexual aggression.

\section{Current Study}

To provide the first longitudinal assessment of the confluence model involving pornography use, the current study tested the association between pornography use and sexual aggression using two independent longitudinal panel samples of male Croatian adolescents. Following the conceptual model, we focus on whether antecedent levels of hostile masculinity, impersonal sexuality, and pornography use were associated with subsequent changes in the odds of self-reported sexual aggression. If pornography use can be said to cause sexual aggression for men who are at risk of engaging in sexual aggression, as stipulated by the confluence model (Hald \& Malamuth, 2015; Malamuth et al., 2000; Malamuth \& Hald, 2017), positive two- and three-way interactions between pornography use and the risk factors of hostile masculinity and impersonal sexuality should be associated with increases in the odds of sexual aggression over time. Of further interest is whether any relationships that may emerge between pornography use 
and sexual aggression will remain significant after controlling for potential confounds (masturbation frequency as a proxy for sexual interest, pubertal status, impulsiveness, and sensation seeking, and social desirability).

Given the lack of longitudinal explorations into the central theoretical conceptualization of the link between pornography use and sexual aggression, this study—with its internal replication component - has the potential to advance our understanding of the target relationship in a systematic and robust way. Such insights could have important ramifications for sexual aggression prevention and intervention efforts.

\section{METHOD}

\section{Participants and Procedure}

Data from this study were drawn from the Zagreb and Rijeka panel samples recruited for the PROBIOPS project. ${ }^{1}$ This project included 936 second year male high-school students $\left(M_{\text {age }}\right.$ $=16.20, S D=0.55)$ from 59 of 70 schools in the city of Zagreb, the capital of Croatia, and the surrounding area to participate in a 6-wave longitudinal study concerning sexual media use. A further sample of 743 second year high-school students $\left(M_{\mathrm{age}}=15.89, S D=0.54\right)$ were recruited from 14 of 22 schools in the city of Rijeka, the third largest city in Croatia. While the participants in the Zagreb panel completed all measures online, the Rijeka panel used pen and paper assessments conducted in classrooms during school hours under the supervision of a research assistant. In these cases, privacy screens were placed between students to maintain confidentiality and teachers were generally not present during assessments ( $>90 \%$ of assessments). In the few exceptions that occurred, teachers remained at the front of the room

\footnotetext{
${ }^{1}$ The PROBIOPS data have been used for several publications concerning adolescent pornography use. Specific topics have included: sexual activity, body surveillance, compulsive pornography use, religiosity, subjective wellbeing, sexual permissiveness, and sexual risk taking (http:// http://probiops.ffzg.hr/papers-published/). For further details, see https://osf.io/4q68c/
} 
with the research assistant who was collecting data and thus were not in a position to observe what their students were reporting. The first assessments were conducted in 2015 and follow-up waves occurred in approximately 5 month intervals. Across both panels, all measures were administered in Croatian. At the outset of the study, approximately one quarter (Zagreb: 26\%; Rijeka: 26\%) of the participants in each panel were coitally experienced, and by the final wave, these figure rose to slightly more than half (Zagreb: 54\%; Rijeka 53\%) (see Table 1). Further demographic characteristics are shown in Table 2.

All questionnaires contained contact information for youth psychological health services. Lottery-based compensation for participation (vouchers worth about 13.5 EUR / 16 \$US) was only offered to the online panel members. Following national guidelines for ethical research with minors, students were asked to provide informed consent at each wave. Prior to the study launch, their parents were sent information about the longitudinal study and its aims. All procedures were reviewed and approved by the Ethical Research Committee of the University of Zagreb.

\section{Measures}

\section{Sexual Aggression}

Sexual aggression was measured at waves T1-T5 in the Zagreb sample and waves T2-T6 in the Rijeka sample. It was initially assessed with a single-item general indicator that was previously used in research involving adolescents (Ybarra et al., 2011): "How many times have you kissed, touched, or done anything sexual with another person when that person did not want you to do so?" After the baseline assessment, the phrase "How many times" was replaced with "In the last 6 months." Responses were measured with a three-point scale: "Never," "once," and “several times." Consistent with Ybarra et al. (2011), responses were dichotomized by collapsing together "once" and "several times." While reports of sexual aggression in the Zagreb $(3.03 \%$ - 
$5.29 \%$ ) and Rijeka (3.76\%-7.54\%) panels were similar to results in previous surveys of adolescents (Ybarra et al., 2011) when based on all available cases, after adjustments for missing data were made through multiple imputation, estimated prevalence of sexual aggression were higher at each wave $(9.17 \%-11.21 \%)$. Correlations across waves ranged between $r(934)=.01$ and $r(934)=.23$ in the Zagreb panel and between $r(741)=.10$ and $r(741)=.30$ in the Rijeka panel.

\section{Hostile Masculinity}

In confluence model research, hostile masculinity has been operationalized in a variety of ways, but nearly every operationalization has employed a measure of hostility towards women, either on its own, or in combination with other constructs (e.g., sexual dominance, adversarial sexual beliefs, negative masculinity, etc.; see Malamuth et al., 1995, 2000; Malamuth \& Ceniti, 1986; Vega \& Malamuth, 2007). In the current study, hostile masculinity was assessed at waves T1, T2, T4, and T5 in the Zagreb panel, and T2-T6 in the Rijeka panel using a 5-item adapted version of Lonsway and Fitzgerald's (1995) Hostility Towards Women scale ${ }^{2}$. Examples of items used in the current study included: "I feel that many times women flirt with men just to tease them or hurt them" and "Women are responsible for most of my troubles." Responses were collected on a 5-point scale that ranged from "strongly disagree" to "strongly agree" and summed into a composite indicator (Cronbach $\alpha$ 's were between .72 and .84 in the Zagreb panel and between .79 and .84 in the Rijeka panel). Correlations across waves ranged between $r(934)=$ .46 and $r(934)=.55$ in the Zagreb panel and between $r(741)=.51$ and $r(741)=.66$ in the Rijeka panel.

\footnotetext{
${ }^{2}$ The full 10-item scale was employed to measure Hostile Masculinity in the Zagreb panel, with a 3-form planned missing design (Graham et al., 2006). All participants were randomly assigned to one of three forms of the scale. Each of these forms was composed of 8 items. Missing responses were then imputed with full information maximum likelihood-based regression approach. For comparison purposes, the current study focused on a reduced set of 5 items that were employed in the Rijeka panel.
} 


\section{Impersonal Sexuality}

Similar to hostile masculinity, the construct of impersonal sexuality (sometimes referred to as sexual promiscuity in earlier research) has been measured in a variety of ways. Most commonly, it has been operationalized as an aggregate of number of sexual partners and age of first intercourse (Baer et al., 2015; Hald et al., 2010; Malamuth et al., 1991, 2000). In the current study, impersonal sexuality also reflected number of sexual partners as well as age of first intercourse. ${ }^{3}$ At each wave, participants were asked if they had sexual intercourse. If participants confirmed that they had, they were further asked: "In total, with how many different people did you have sexual intercourse since your first time?" Participants who did not report sexual intercourse were assumed to have had no sexual partners. ${ }^{4}$ Study wave of first reported intercourse was used as a proxy for age of first intercourse. ${ }^{5}$ If participants had not had intercourse by the last wave of the study, they were assigned a value of zero. Number of partners and reverse-coded age at first intercourse (zero-order correlations between the two variables ranged between $r[195]=.59$ and $r[142]=.70$ in the Zagreb panel and between $r[348]=.62$ and $r[285]=.74$ in the Rijeka panel) were then standardized and averaged to create a composite

\footnotetext{
${ }^{3}$ We had originally pre-registered an operationalization of impersonal sexuality that was based solely on number of partners. The results with respect to impersonal sexuality did not differ substantially from those presented below and can be found here: https://osf.io/gn3ey/. Upon further consideration, we were concerned that this operationalization departed too far from Malamuth's formulation of impersonal sexuality and updated our operationalization and analyses accordingly.

${ }^{4}$ In cases when participants lacked data for a specific wave but their reported number of sexual partners was stable across the preceding and following assessments, the missing data were replaced with the number of sexual partners that they reported before and after the gap. For example, if a participant reported one lifetime partner at both T1 and $\mathrm{T} 3$, missing data at $\mathrm{T} 2$ were replaced with one lifetime partner.

${ }^{5}$ In cases where missing information occurred between an indication of no intercourse and first reported intercourse, the wave of first reported intercourse was modified to reflect the possibility that first intercourse occurred during the period in which data were missing. In this case, the assumed age at first intercourse was calculated by averaging between the wave of first reported intercourse and the first wave of missing data that preceded the report of first intercourse. For example, if a participant reported no intercourse at T1, and first intercourse at T4, but had missing data at $\mathrm{T} 2$ and $\mathrm{T} 3$, then their assumed wave of first intercourse was defined as $(\mathrm{T} 4+\mathrm{T} 2) / 2=\mathrm{T} 3$. A similar approach was used when participants were lost to follow-up without identifying a wave of first intercourse. In this case, their wave of first intercourse was defined as the average between the last wave they reported no intercourse and T6. For example, if a participant reported no intercourse at $\mathrm{T} 1$, but supplied no further sexual behavior data, their assumed age of first intercourse was $(\mathrm{T} 1+\mathrm{T} 6) / 2=\mathrm{T} 3.5$.
} 
indicator of impersonal sexuality. Temporal stability of the measure of impersonal sexuality was satisfactory $(r[934]=.74-r[934]=.90$ in the Zagreb panel and $r[741]=.84-r[741]=.96$ in the Rijeka panel). In the Rijeka panel, the composite measure of impersonal sexuality was correlated positively with recreational attitudes when measured at the same wave $(r[207]=.17-$ $r[224]=.23)$. A similar association was found in the Zagreb panel at $\mathrm{T} 4(r[111]=.20, p=.033)$. Pornography Use

Consistent with past confluence model research (Baer et al., 2015; Hald et al., 2010; Kohut et al., 2020; Malamuth et al., 2000; Vega \& Malamuth, 2007) and, indeed, most research involving exposure to pornography (Kohut et al., 2020; Short et al., 2012), pornography use was assessed with a single item at each wave in both panels. After defining pornography as "any material which openly depicts sexual activity; material which shows naked bodies but not sexual intercourse or other sexual activity does not belong to pornography as here defined," participants were asked about the frequency of use in the past 6 months. Response options ranged from: $1-$ "not once" to 8 - "several times a day." Stability coefficients for the indicator ranged between $r(934)=.57$ and $r(934)=.64$ in the Zagreb panel and between $r(741)=.55$ and $r(741)=.75$ in the Rijeka panel.

\section{Masturbation}

The frequency of masturbation was used as a proxy for solitary sexual interest and was assessed twice in the Zagreb panel (T1 and T4) and once in Rijeka (T6) with the following question: "How often have you masturbated in the past six months?" An 8-point scale ranging from "not once" to "several times a day" was used to anchor answers. In Zagreb, the T1 and T4 $(r[129]=.62)$ average was used as the estimated masturbation frequency.

\section{Pubertal Status}


The construct was measured at baseline, in both panels, using a single item relative-rating indicator of the onset of puberty ("In comparison to others, your physical development began...") that has been used in previous research (Petersen et al., 1988). Answers were anchored using 5-point scale ranging from 1 - "much earlier than in your peers" to 5 - "much later than in your peers."

\section{Sensation Seeking}

Sensation seeking was measured with the Stephenson et al. (2003) brief 4-item composite at T2, T3, and T5 in the Zagreb panel and T2-T6 in the Rijeka panel. Example items included "I would like to explore strange places" and "I like new and exciting experiences, even if I have to break the rules." Responses were measured on a 5-point scale ranging from 1 - "It does not relate to me at all" to 5 - "It relates to me completely." Responses were summed with higher scores indicating more sensation seeking (Cronbach $\alpha$ was in the .76-.83 range in Zagreb and in the $.74-.83$ range in Rijeka). Correlations across waves ranged from $r(101)=.71$ to $r(112)=.73$ in the Zagreb panel and from $r(278)=.65$ to $r(224)=.78$ in the Rijeka panel. Sensation seeking scores were averaged across waves and used as a time-invariant control in both panels.

\section{Impulsiveness}

Impulsiveness was measured with an adapted 8-item version of the Barratt Impulsiveness Scale-Brief (Steinberg et al., 2013) at T4 in the Zagreb panel and T2, T3, and T6 in the Rijeka panel. Example items included "I do things without thinking" and "I am future oriented." Responses were rated on a 4 point scale ranging from 1 - "Never/Rarely" to 4 "Almost Always/Always." Responses were summed so that larger scores indicated higher impulsiveness (Cronbach $\alpha$ was .64 in Zagreb and between .75 and .79 in Rijeka). Correlations across waves in 
the Rijeka panel were in the $r(193)=.64-r(204)=.68$ range. Impulsiveness scores in the Rijeka panel were averaged to create a time invariant estimate.

Social Desirability

Social desirability was measured with an 11-item version of the Marlowe-Crowne Social Desirability scale (Reynolds, 1982) that was included in wave T5 in the Zagreb panel and waves T2 and T4 in the Rijeka panel. Example items included "I'm always willing to admit it when I make a mistake" and "I am sometimes irritated by people who ask favors of me." Responses, which were collected using a yes/no scale, were reverse coded and summed to create an ordinal scale with higher scores indicating higher social desirability (Cronbach $\alpha$ in the Zagreb panel was .51 and in the Rijeka panel: .59-.61). Temporal stability in the Rijeka panel was $r(200)=$ .53. Social desirability scores in the Rijeka panel were averaged to create a time invariant estimate.

\section{Analytic Plan}

We analyzed the data from Zagreb and Rijeka separately because we felt that there were important cultural differences between the panels. Since the 1990s, Zagreb and Rijeka have constituted different micro-cultures in that Zagreb generally tends to be more politically conservative, nationalist, and religious than Rijeka. For example, Zagreb was relatively split on the referendum about the constitutional definition of marriage, while Rijeka was homogeneously against the heterosexist definition. This may partially explain why we have found some systematic differences across the panels, among both genders, in the frequency of pornography use (consistently higher in Zagreb) and level of religiosity (consistently higher in Zagreb). This, in our view, confirms potential differences in adolescents' sexual socialization in areas which may be relevant to the variables under study. 


\section{Multiple Imputation}

Because a lagged design requires complete data on all independent variables at waves $t$ and the dependent variable at waves $t+1$, complete observations were limited to $n=197(21 \%)$ males in the Zagreb panel and $n=412(56 \%)$ males in the Rijeka panel. Male participants without complete data in the Zagreb panel were more likely to be attending vocational school, $\chi^{2}(1)=12.12, p=.001$, had lower grades in their first year of studies, $t(934)=-3.96, p<.001$, were higher in sensation seeking, $t(352)=3.22, p=.001$, were higher in hostile masculinity at baseline, $t(934)=4.00, p<.001$, and, at T4, and reported more sexual partners at baseline, $t(863)=5.18, p<.001 .^{6}$ Effect sizes for these differences tended to be small (Cohen's $d$ 's ranged from 0.26 to 0.35 and Cramer's V was 0.25 ). Similarly, male participants without complete data in the Rijeka sample were significantly older, $\chi^{2}(3)=9.81, p=.020$, more likely to be attending vocational school, $\chi^{2}(1)=10.77, p=.001$, had lower grades in their first year of studies, $t(430)=4.02, p<.001$, were higher in sensation seeking, $t(352)=3.22, p=.001$, were higher in hostile masculinity at baseline, $t(377)=3.43, p=.001$, through $\mathrm{T} 4$, reported more sexual partners at baseline, $t(218)=6.61, p=.001$, through $\mathrm{T} 4$, and reported significantly more pornography use, but only at T3, $t(156)=2.29, p=.024$. With the exception of the number of partners at baseline (Cohen's $d=0.90$ ), effect sizes ranged from small to medium (Cohen's $d$ 's ranged from 0.34 to 0.39 and Cramer's V ranged from 0.15 to 0.16 ). Reports of sexual aggression did not significantly differ between participants with and without complete data in either panel.

Multiple imputation was employed to estimate missing data across all of the focal variables in this study as it corrects for the biases that may be introduced when data are not

\footnotetext{
${ }^{6}$ Corrections for multiple comparisons were not employed in these tests to improve sensitivity to detect possible differences between the full and subsamples (minimizing type II error).
} 
Missing at Complete Random (Graham, 2009). ${ }^{7}$ Because of the large number of predictor variables, values were imputed for aggregated summary variables rather than for all items included in these variables. It should be noted that all internal consistency coefficients and stability coefficients for time-invariant predictors (e.g., masturbation, impulsiveness, sensation seeking, and social desirability) described in the Method section were based on the analysis of complete cases only. Of further note, the imputation process was applied to wide- rather than long-form data. In this case, missing values for model predictors were imputed using all available information from the other predictors of the model measured at every wave. Imputation of the dependent variable, however, relied on time-varying predictors and their interactions at the preceding wave, as well as all time-invariant predictors. This method was integral for ensuring that all of the final analytic model's parameters were included in the imputation process for sexual aggression (Graham, 2009). Furthermore, the use of wide- rather than long-formatted data was necessary so that sexual aggression at time $t+1$ could be predicted by sexual aggression at time $\mathrm{t}$ without allowing for the possibility that different imputations would be made for connected pairs of missing observations in sexual aggression that occur in long-form data (see Fig. 1). For example, if a participant did not report sexual aggression at the T3 assessment, two records would be missing for this participant in long-form data, one in the variable that represents aggression at time $t$ (in this case, T3) and one in the variable that represents aggression at time $t+1$ (see Fig. 1). If imputation was to be applied to the long-form data, each of the missing values in this pair would be estimated independent from one another, despite the fact that they reflect the same missing observation.

\footnotetext{
${ }^{7}$ The initial pre-registration involved a planned analysis that was limited to the number of available observations and an earlier version of the paper based on this approach can be found here: https://osf.io/j63a4/. The current approach, involving multiple imputation, was only adopted after receiving feedback from the peer-review of the original paper. The only inferential difference that emerged after data imputation was that hostile masculinity was associated with an increase in the probability of subsequent sexual aggression in the Rijeka panel.
} 
Following Graham's (2009) recommendation, 40 datasets were imputed using the mice package in R (van Buuren \& Groothuis-Oudshoorn, 2011) with the maximum number of iterations set to 20 . The analytic plan described below was conducted on each of these datasets and results were pooled by Rubin's Rules before inferences were made. Following the multiple imputation, our analyses included data from 936 participants with 2,808 observations in the Zagreb panel (sexual aggression predicted at T2, T3, T5 using independent variables from T1, T2, and T4) and 743 participants with 2,972 observations in the Rijeka panel (sexual aggression predicted at T3, T4, T5, and T6 using independent variables from T2, T3, T4, and T5). Please note that data were not imputed for waves in which either the independent variables or the dependent variables were not assessed.

\section{Testing the Confluence Model}

If pornography use causes sexual aggression, but only among men who are high in other risk factors (e.g., hostile masculinity and impersonal sexuality), then self-reported sexual aggression at any given wave should be a function of positive three-way and two-way interactions between pornography use, hostile masculinity, and impersonal sexuality at the preceding wave- - while controlling for self-reported sexual aggression at the preceding wave. In this model, significant effects for pornography use parameters would indicate relationships between pornography use and subsequent change in the odds of self-reported sexual aggression across time. To this end, generalized linear mixed modeling was used to predict the probability of self-reported sexual aggression at waves $t+1$ using previously reported pornography use, hostile masculinity, and impersonal sexuality, all two-way and three-way interactions between these constructs, and self-reported sexual aggression at waves $t$. Because sexual aggression was dichotomized, we employed a binomial distribution and logit link function. Following the advice 
of Heck et al. (2012), we had initially pre-registered a plan to model the dependencies between measurement occasions by allowing residuals to correlate. ${ }^{8}$ We decided, however, to change this approach when we discovered that others have argued that a random intercept model is more appropriate when examining time varying predictors in longitudinal data (Szmaragd et al., 2013). Preliminary estimation of unconditional (intercept only) models using only complete cases indicated that while a reasonable amount of variation in sexual aggression could be attributed to the clustering of measures within individual participants $(\mathrm{ICC}=.36$ in the Zagreb panel; ICC $=$ 0.30 in the Rijeka panel) little variation in sexual aggression could be attributed to the school clusters from which participants were sampled (ICC $=.09$ in the Zagreb panel; ICC $=.02$ in the Rijeka panel). Consequently, school-based data nestedness was ignored in the following analyses.

Two analytic models were carried out in each sample. The first model (Model 1) included hostile masculinity, impersonal sexuality, and pornography use and their interactions, while the second model also included time invariant controls (masturbation frequency, pubertal status, impulsiveness, sensation seeking, and social desirability). ${ }^{9}$ Model 1 included 2,808 observations in the Zagreb panel and 2,972 observations in the Rijeka panel. Using the ICC estimations, observations nested within participants (three observations per participant in Zagreb and four in Rijeka) reduced the effective number of observations to 1,632 in the Zagreb panel and 1,857 in the Rijeka panel (McCoach \& Adelson, 2010). If the effect size of the critical interaction is $d=$ $0.34\left(f^{2}=.03\right.$ is the average reported effect size for this three-way interaction in previous

\footnotetext{
${ }^{8}$ For details, see https://osf.io/t5nhx/

${ }^{9}$ We had originally pre-registered a plan that included a measure of testosterone among the control variables in the Rijeka panel. It was ultimately not included in the analyses presented below. Testosterone measurement was dropped for three reasons. First, it was uncorrelated with all variables of interest in this study. Second, its inclusion would have severely reduced the number of available observations (much more so than the other control variables), due to the fact that only 252 male adolescents provided a saliva sample. Finally, its inclusion would have interfered with the comparability of results across the two panels.
} 
research; see Baer et al., 2015; Malamuth et al., 2000), the equivalent odds ratio is approximately 2.09, when $P_{0}=.05$ (see Table 1 in Chen et al., 2010). With this information, and assuming that the other variables in the model account for $33 \%$ of the variance in sexual aggression (see Baer et al., 2015), power for a two-tailed test was estimated (using G*Power 3.1.9.2; Faul, Erdfelder, Lang, \& Buchner, 2009) to be nearly $100 \%$ in both the Zagreb and Rijeka panels.

We used R (version 3.5.3), with the glmer function from the lme4 package (Bates et al., 2015) for all analyses. Although the Gauss-Hermite quadrature approach to parameter estimation is recommended for generalized linear mixed models with binary data (Bolker et al., 2009), we encountered problems with convergence in some imputed data sets, and consequently adopted the use of a penalized quasi-likelihood method instead. All data and syntax used in this study are available online. ${ }^{10}$

\section{RESULTS}

Zero-order correlations between all variables in the Zagreb panel are shown in Table 3. No significant associations were found between sexual aggression and contemporaneously measured predictor variables. Further, correlations between independent variables and sexual aggression at the following wave tended to be weak and non-significant. These correlations ranged from $r=-.01$ to $r=.14$ for hostile masculinity, $r=.00$ to $r=.24$ (the latter coefficient was significant, $p=.041$ ) for impersonal sexuality, and $r=-.06$ to $r=.10$ for pornography use.

A somewhat similar pattern of correlations emerged for the focal variables in the Rijeka panel (see Table 4). In this case, however, hostile masculinity was significantly correlated with contemporaneously measured sexual aggression at T3, $r=.13, p=.006$, and at $\mathrm{T} 4, r=.11, p=$ .020 , but impersonal sexuality and pornography use were not associated with contemporaneous sexual aggression at any wave. As with the Zagreb panel, correlations between independent

\footnotetext{
${ }^{10}$ See https://osf.io/gn3ey/
} 
variables and sexual aggression at the following wave were similar in magnitude and largely non-significant. These correlations ranged from $r=.03$ to $r=.17(p=.004)$, for hostile masculinity, $r=.00$ to $r=.15$ for impersonal sexuality, and $r=-.03$ to $r=.12$ for pornography use.

Model 1 consisted of a basic lagged test of the confluence model. In this model, sexual aggression at subsequent waves $(t+1)$ was predicted by hostile masculinity, impersonal sexuality, pornography use, their interactions, and sexual aggression measured at the previous wave $(t)$. Non-independence across measurement occasions was accommodated by including a random intercept for participants. Summary results for both panels can be found in Table 5 . Among the confluence model components, only hostile masculinity was associated with subsequent sexual aggression in the Rijeka, $O R=1.26, b=0.23, p=.029$, but not the Zagreb panel, $O R=1.07, b=0.07, p=.589$. No further significant effects were found for impersonal sexuality, pornography use or — critically for the confluence model—any of the interactions between the model components. Independent of the confluence model components, reported acts of sexual aggression were inconsistently associated with higher odds of reporting sexual aggression. The link was significant in the Rijeka, $O R=3.73, b=1.32, p<.001$, but not the Zagreb panel, $O R=1.25, b=0.22, p=.632$.

In second model, Model 1 was extended by adding control variables (see Table 6). The focal indicators implied by the confluence model remained non-significant in the Zagreb panel. In the Rijeka panel, hostile masculinity ceased to be significantly related to subsequent sexual aggression once the control variables were included, $O R=1.19, b=0.17, p=.115$. In the Rijeka panel, only sensation seeking, $O R=1.09, b=0.09, p=.005$, and previous sexual aggression, $O R$ 
$=3.70, b=1.31, p<.001$, were associated with sexual aggression. No significant associations were observed in the Zagreb panel.

\section{Exploratory Contemporaneous Models}

Because we generally failed to identify confluence model correlates of subsequent sexual aggression, we decided to proceed with a non-lagged or "contemporaneous" test (Model 3) of the confluence model. In this final generalized linear mixed model, sexual aggression at time $t$ was predicted by hostile masculinity, impersonal sexuality, and pornography use at time $t$.

Essentially, this is a cross-sectional analysis - thus, more comparable to previous analyses of the confluence model - that used data pooled across multiple waves of data collection. As shown in Table 6, only hostile masculinity was positively associated with sexual aggression measured at the same time in the Zagreb panel, $O R=1.33, b=0.29, p=.038$. Similar findings were observed in Rijeka, where hostile masculinity, $O R=1.44, b=0.36, p=.001$, but not other components of the confluence model (or their interactions), was significantly associated with sexual aggression.

\section{DISCUSSION}

This is the first study to test the confluence model's (Malamuth et al., 2000; Malamuth \& Hald, 2017) causal assumptions about pornography use in two panels of male Croatian adolescents. According to the theory, pornography use is a risk factor for sexual aggression among men who exhibit hostile masculinity and impersonal sexuality — characteristics that have been found to predispose men to sexual aggression. While the asserted relationships are typically supported in cross-sectional research (Baer et al., 2015; Malamuth et al., 2000; Vega \& Malamuth, 2007), we were unable to find studies that have examined these associations prospectively. In contrast to the widespread appeal of the confluence model, the current study 
does not support this conceptualization of the causal role of pornography use in sexual aggression in two independent samples of adolescents.

There are several sample-specific reasons that may account for the current study's lack of support for the confluence model. For example, there are clear differences between the current study and past findings in terms of participants' age and cultural environment. Previous research has been largely restricted to samples of young North American adults (Baer et al., 2015; Malamuth et al., 2000; Vega \& Malamuth, 2007). Considering that Malamuth et al. (2000) have argued that pornography contributes to sexual aggression by activating and reinforcing preexisting sexually aggressive cognitions, emotions, and attitudes, the failure to find relevant associations in the current sample may simply reflect a sample that is too young to have (fully) developed cognitive systems that would pre-dispose them to sexual aggression. Alternatively, cultural differences between the previous North American samples and the Croatian panel samples may be of concern. Croatia is particularly notable for its contemporary religiosity (it is one of the most religious countries in the European Union; Luijkx, Halman, Sieben, Brislinger, \& Quandt, 2016) and relatively low levels of sexual permissiveness (Štulhofer \& Rimac, 2009). However, it is not clear how religiosity might affect the relationship between pornography use and sexual aggression among high-risk male adolescents. Nevertheless, if either age or cultural differences were related to the failure to observe the expected relationships in the current study, it would suggest important boundary (age- or culture-specific) conditions that need to be considered in future research.

Low correlations between impersonal sexuality and sexual aggression may have also undermined the association between pornography use and sexual aggression by suppressing two and three-way interactions involving hostile masculinity, impersonal sexuality, and pornography 
use. It may be the case that the liberties we took when estimating age of first intercourse (i.e., wave of first intercourse) for participants with missing data compromised the integrity of our operationalization of impersonal sexuality. However, the positive correlations, modest as they were, between our indicator of impersonal sexuality and recreational attitudes towards sex, as well as its associations with hostile masculinity and sensation seeking, all speak to the validity of our operationalization. Another possibility is that impersonal sexuality, as it has been operationalized in confluence model research, may be less predictive of sexual aggression among adolescents than young adults. It should be noted that the range of and variance in the number of sexual partners, as well as age at first intercourse, are necessarily larger among young adults than adolescents. Other factors remaining equal, such differences may attenuate correlations between impersonal sexuality and sexual aggression in younger samples. This, in turn, could reduce associations between pornography use and sexual aggression among high-risk participants.

Aside from not demonstrating the expected "confluence" in either lagged or crosssectional regression models, there are two other noteworthy findings. First, hostile masculinity was associated with self-reported sexual aggression in both of our panels when measured at the same wave, corroborating findings from cross-sectional research (Baer et al., 2015; Malamuth, 1986; Malamuth et al., 1991, 1995, 2000; Vega \& Malamuth, 2007). This extends predictive validity of the hostile masculinity construct to non-North American adolescents. Moreover, findings from one panel in the current study suggests that, at any given point in adolescence, hostile masculinity can predict an increase in the probability of subsequent sexual aggression, providing some evidence that hostile masculinity may play a causal role in sexual offending though we hasten to point out that this effect did not survive the addition of control variables. 
Future research is needed to both confirm this finding and determine why it may not be robust with respect to sample differences and the control variables used in this study.

The second and perhaps most important issue, given the focus of this paper, is that pornography use, when considered on its own, but also in confluence with other risk factors for sexual aggression, was not substantially associated either with contemporaneously measured sexual aggression or changes in the probability of subsequent sexual aggression. This may appear to be a controversial finding, but it is compatible with literature that is replete with small and inconsistent findings (Ferguson \& Hartley, 2009, 2020; Fisher et al., 2013; Fisher \& Barak, 1991, 2001; Fisher \& Grenier, 1994; Fisher \& Kohut, 2020; Grubbs et al., 2019; Kohut et al., 2020; Seto et al., 2001).

Some may point to Wright et al.'s (2016) recent meta-analysis as evidence that the association between pornography use and sexual aggression is neither weak nor inconsistent. In short, this meta-analysis, conducted across 22 correlational and longitudinal studies involving 20,820 participants, reported small but reliable average associations between pornography use and both verbal, $r=.30$, and physical, $r=.20$, sexual aggression. Unfortunately, many of the studies included in this meta-analysis did not account for possible confounding, likely inflating the focal associations. Further, among the studies that controlled for confounding variables, Wright et al. appear to have overlooked diminished effect sizes that resulted from the inclusion of potential confounders. For example, Wright et al., reported that Ybarra et al. (2011) found an association between pornography use and sexual aggression of .38, which was then adjusted to .43 , to account for the unreliability of the measures of pornography and sexual aggression. This is almost double the effect size Ybarra et al. actually reported after including control variables in their model $(r=.23 ; O R=2.4)$. Our observations of Wright et al.'s over-reliance on inflated 
effect sizes are corroborated by more recent meta-analytic findings which indicate that once control variables are properly accounted for, non-violent pornography use is generally not associated with sexual aggression (Ferguson \& Hartley, 2020).

In this context, it should be noted that although nearly all of the controls considered in the current study were related to pornography use, they were generally not found to be related to self-reported sexual aggression. The one notable exception was sensation seeking and this finding is in line with the previously reported association between sensation seeking and the perpetration of sexual harassment in a sample of American adolescents (Brown \& L'Engle, 2009). Particularly surprising was the finding that masturbation frequency, the proxy for sexual interest (or "sexual drive" in the confluence model terminology) was unrelated to sexual aggression. It should be noted, however, that Baer et al. (2015) also failed to observe a significant correlation between their measure of sexual interest (which included an indicator of masturbation frequency) and sexual aggression. The association between these two variables only existed among young men who were high in hostile masculinity and impersonal sexuality. Regardless, future research should control for potential confounding variables before making any suggestions about a causal relationship between pornography use and sexual aggression. Sensation seeking, in particular, stands out as relevant candidate for this use.

\section{Strengths and Limitations}

The current pre-registered study is the first to prospectively test the confluence model propositions about pornography use and sexual aggression with an internal replication component. Nevertheless, our study had several shortcomings that should be noted. Of particular concern is the substantial degree of missing data due to factors such as school absenteeism and participant attrition. Elsewhere, we have described how such loss of participants can constitute a 
challenge to validity of pornography research, because such participants often exhibit qualities that are theorized to make them especially vulnerable to the effects of pornography (Štulhofer et al., 2020). To address this concern, we imputed missing values using multiple imputation, which is considered a best-practice option, even when information is missing not at random (Graham, 2009). Nevertheless, such efforts may not have fully accounted for biases that may have been introduced by attrition and readers should consider this issue when weighing our findings.

It is also important to consider the nature of the pornography used by adolescents in our samples. The current analyses relied on a measure of general pornography use, rather than the use of sexually violent pornography. Malamuth (2018) argued that heavy pornography use, but particularly heavy use of violent pornography, should contribute to sexual aggression among men with high pre-disposed risk, so it may be possible that more clear associations would have been found had the current study examined violent pornography use specifically. However, it should be noted that past confluence model work has repeatedly found effects with general measures of pornography use rather than specific measures of violent pornography use (Baer et al., 2015; Malamuth et al., 2000; Vega \& Malamuth, 2007). Perhaps this is because adult men who are high in hostile masculinity and impersonal sexuality report that a greater proportion of their overall pornography use involves violent or coercive content (Baer et al., 2015). Whether or not a similar pattern of pornography use is also found among adolescent men who are high in predisposed risk for committing sexual violence remains to be determined.

The use of time-invariant control variables is a further limitation of the study design. Indeed, it is possible that the failure to use time-varying control variables in our analyses may have reduced the magnitude of the resulting associations between the control variables and the change in probability of sexual aggression at any given wave. Unfortunately, in this case, we 
were limited by the constraints in the available dataset because this consideration was not foreseen when these longitudinal panel projects were initially designed. In an ideal lagged study, time varying control variables should be available at each wave of assessment.

Another important consideration is that the data used in this study, and, in fact, the confluence model more broadly, are only relevant for understanding acts of sexual aggression that are perpetrated by males. Considering the evidence that a non-trivial amount of sexual aggression is also perpetrated by female adolescents (Ybarra et al., 2011), future explorations should consider how pornography use may interact synergistically with factors that predispose young women to engage in sexual aggression.

Finally, the operational definition of sexual aggression in this study was limited to physical acts of sexual aggression. Wright et al. (2016) have previously indicated that associations between pornography use and verbal sexual aggression (i.e., sexual harassment) tend to be stronger than those for physical sexual aggression. Unfortunately, while the PROBIOPS panels included measures of online sexual harassment victimization, they did not include measures of sexual harassment perpetration, so the current data cannot speak to the possible temporal relationships between pornography use and subsequent verbal sexual aggression.

\section{CONCLUSIONS}

While the current study did not support the confluence model argument that pornography use contributes causally to sexual aggression among men who are predisposed to sexual violence, our findings — which are consistent across two independent large-scale panels — should not be taken as proof that this proposition should be abandoned. Given the limitations outlined above, and sampling differences between the current study and previous approaches, caution is 
certainly warranted when interpreting the results. It is our hope that the current study will motivate more longitudinal research of the topic in different sociocultural settings. With more data, we will be in a much better position to decide which aspects of the confluence model, if any, need revising. 


\section{Compliance with Ethical Standards}

\section{Disclosure of Potential Conflicts of Interest}

This work was supported by the Croatian Science foundation [grant \#9221 awarded to the last author] and the University of Zagreb.

\section{Research Involving Human Participants and/or Animals}

All procedures human participants were in accordance with the ethical standards of the Ethical Research Committee of the University of Zagreb and with the 1964 Helsinki declaration and its later amendments or comparable ethical standards.

\section{Informed Consent}

Informed consent was obtained from all individual participants included in the study. 


\section{References}

Baer, J. L., Kohut, T., \& Fisher, W. A. (2015). Is pornography use associated with anti-woman sexual aggression? Re-examining the Confluence Model with third variable considerations. The Canadian Journal of Human Sexuality, 24(2), 160-173. https://doi.org/10.3138/cjhs.242-A6

Bates, D., Maechler, M., Bolker, B. M., \& Walker, S. (2015). Fitting linear mixed-effects models using lme4. Journal of Statistical Software, 67(1), 1-48. https://doi.org/10.18637/jss.v067.i01

Beyens, I., Vandenbosch, L., \& Eggermont, S. (2015). Early adolescent boys' exposure to internet pornography: Relationships to pubertal timing, sensation seeking, and academic performance. Journal of Early Adolescence, 35(8), 1045-1068. https://doi.org/10.1177/0272431614548069

Bolker, B. M., Brooks, M. E., Clark, C. J., Geange, S. W., Poulsen, J. R., Stevens, M. H. H., \& White, J. S. S. (2009). Generalized linear mixed models: A practical guide for ecology and evolution. Trends in Ecology and Evolution, 24(3), 127-135.

https://doi.org/10.1016/j.tree.2008.10.008

Bonino, S., Ciairano, S., Rabaglietti, E., \& Cattelino, E. (2006). Use of pornography and selfreported engagement in sexual violence among adolescents. European Journal of Developmental Psychology, 3(3), 265-288. https://doi.org/10.1080/17405620600562359

Brown, J. D., \& L'Engle, K. L. (2009). X-Rated sexual attitudes and behaviors associated with U.S. early adolescents' exposure to sexually explicit media. Communication Research, 36(1), 129-151. https://doi.org/10.1177/0093650208326465

Carvalho, J., \& Nobre, P. (2013). Dynamic factors of sexual aggression: The role of affect and 
impulsiveness. Criminal Justice and Behavior, 40(4), 376-387.

https://doi.org/10.1177/0093854812451682

Chang, F. C., Chiu, C. H., Miao, N. F., Chen, P. H., Lee, C. M., \& Chiang, J. T. (2016).

Predictors of unwanted exposure to online pornography and online sexual solicitation of youth. Journal of Health Psychology, 21(6), 1107-1118.

https://doi.org/10.1177/1359105314546775

Chen, H., Cohen, P., \& Chen, S. (2010). How big is a big odds ratio? Interpreting the magnitudes of odds ratios in epidemiological studies. Communications in Statistics: Simulation and Computation, 39(4), 860-864. https://doi.org/10.1080/03610911003650383

Commission on Obscenity and Pornography. (1971). Technical Report of the Commission on Obscenity and Pornography. U.S. Government Printing Office.

Dawson, S. J., Bannerman, B. A., \& Lalumière, M. L. (2014). Paraphilic interests: An examination of sex differences in a nonclinical sample. Sexual Abuse: A Journal of Research and Treatment, 28(1), 20-45. https://doi.org/10.1177/1079063214525645

Eurostat. (2017). Violent sexual crimes recorded in the EU.

https://ec.europa.eu/eurostat/web/products-eurostat-news/-/EDN-20171123-1

Faul, F., Erdfelder, E., Lang, A.-G., \& Buchner, A. (2009). Statistical power analyses using G*Power 3.1: Tests for correlation and regression analyses. Behavior Research Methods, 41(4), 1149-1160. https://doi.org/10.3758/BRM.41.4.1149

Ferguson, C. J., \& Hartley, R. D. (2009). The pleasure is momentary ...the expense damnable? Aggression and Violent Behavior, 14(5), 323-329.

https://doi.org/10.1016/j.avb.2009.04.008

Ferguson, C. J., \& Hartley, R. D. (2020). Pornography and sexual aggression: Can meta-analysis 
find a link? Trauma, Violence, and Abuse. https://doi.org/10.1177/1524838020942754

Fisher, W. A., \& Barak, A. (1991). Pornography, erotica, and behavior: More questions than answers. International Journal of Law and Psychiatry, 14(1-2), 65-83. https://doi.org/10.1016/0160-2527(91)90025-I

Fisher, W. A., \& Barak, A. (2001). Internet pornography: A social psychological perspective on internet sexuality. Journal of Sex Research, 38(4), 312-323. https://doi.org/10.1080/00224490109552102

Fisher, W. A., \& Grenier, G. (1994). Violent pornography, antiwoman thoughts, and antiwoman acts: In search of reliable effects. Journal of Sex Research, 31(1), 23-28. https://doi.org/10.1080/00224499409551727

Fisher, W. A., \& Kohut, T. (2020). Reading pornography: Methodological considerations in evaluating pornography research. Journal of Sexual Medicine, 17(2), 195-209. https://doi.org/10.1016/j.jsxm.2019.11.257

Fisher, W. A., Kohut, T., Di Gioacchino, L. A., \& Fedoroff, P. (2013). Pornography, sex crime, and paraphilia. Current Psychiatry Reports, 15(6), 362-369. https://doi.org/10.1007/s11920-013-0362-7

Fortenberry, J. D. (2013). Puberty and adolescent sexuality. Hormones and Behavior, 64(2), 280-287. https://doi.org/10.1016/j.yhbeh.2013.03.007

Graham, J. W. (2009). Missing data analysis: Making it work in the real world. Annual Review of Psychology, 60, 549-576. https://doi.org/10.1146/annurev.psych.58.110405.085530

Graham, J. W., Taylor, B. J., Olchowski, A. E., \& Cumsille, P. E. (2006). Planned missing data designs in psychological research. Psychological Methods, 11(4), 323-343. https://doi.org/10.1037/1082-989X.11.4.323 
Greenfeld, L. A. (1997). An analysis of data on rape and sexual assault sex offenses and offenders (NCJ No. 163392). Bureau of Justice Statistics. https://bjs.gov/content/pub/pdf/SOO.PDF

Grubbs, J. B., Wright, P. J., Braden, A. L., Wilt, J. A., \& Kraus, S. W. (2019). Internet pornography use and sexual motivation: A systematic review and integration. Annals of the International Communication Association, 42(2), 117-155. https://doi.org/10.1080/23808985.2019.1584045

Hald, G. M., \& Malamuth, N. M. (2015). Experimental effects of exposure to pornography: The moderating effect of personality and mediating effect of aexual arousal. Archives of Sexual Behavior, 44(1), 99-109. https://doi.org/10.1007/s10508-014-0291-5

Hald, G. M., Malamuth, N. M., \& Yuen, C. (2010). Pornography and attitudes supporting violence against women: Revisiting the relationship in nonexperimental studies. Aggressive Behavior, 36(1), 14-20. https://doi.org/10.1002/ab.20328

Hardy, S. A., Steelman, M. A., Coyne, S. M., \& Ridge, R. D. (2013). Adolescent religiousness as a protective factor against pornography use. Journal of Applied Developmental Psychology, 34(3), 131-139. https://doi.org/10.1016/j.appdev.2012.12.002

Heck, R. H., Thomas, S. L., \& Tabata, L. N. (2012). Multilevel modeling of categorical outcomes using IBM SPSS. Routledge.

Kennair, L. E. O., \& Bendixen, M. (2012). Sociosexuality as predictor of sexual harassment and coercion in female and male high school students. Evolution and Human Behavior, 33(5), 479-490. https://doi.org/10.1016/j.evolhumbehav.2012.01.001

Kingston, D. A., Malamuth, N. M., Fedoroff, P., \& Marshall, W. L. (2009). The importance of individual differences in pornography use: Theoretical perspectives and implications for 
treating sexual offenders. Journal of Sex Research, 46(2-3), 216-232.

https://doi.org/10.1080/00224490902747701

Kohut, T., Balzarini, R. N., Fisher, W. A., Grubbs, J. B., Campbell, L., \& Prause, N. (2020). Surveying pornography use: A shaky science resting on poor measurement foundations. Journal of Sex Research, 57(6), 722-744. https://doi.org/10.1080/00224499.2019.1695244

Krahé, B., Berger, A., Vanwesenbeeck, I., Bianchi, G., Chliaoutakis, J., Fernández-Fuertes, A. A., Fuertes, A., de Matos, M. G., Hadjigeorgiou, E., Haller, B., Hellemans, S., Izdebski, Z., Kouta, C., Meijnckens, D., Murauskiene, L., Papadakaki, M., Ramiro, L., Reis, M., Symons, K., ... Zygadło, A. (2015). Prevalence and correlates of young people’s sexual aggression perpetration and victimisation in 10 European countries: A multi-level analysis. Culture, Health and Sexuality, 17(6), 682-699. https://doi.org/10.1080/13691058.2014.989265

Krug, E. G., Dahlberg, L. L., Mercy, J. A., Zwi, A. B., \& Lozano, R. (2002). World report on violence. World Health Organization. https://www.who.int/violence_injury_prevention/violence/world_report/chapters/en/

Lalumière, M. L., \& Quinsey, V. L. (1996). Sexual deviance, antisociality, mating effort, and the use of sexually coercive behaviors. Personality and Individual Differences, 21(1), 33-48. https://doi.org/10.1016/0191-8869(96)00059-1

Luijkx, R., Halman, L., Sieben, I., Brislinger, E., \& Quandt, M. (2016). European values in numbers trends and traditions at the turn of the century. Brill. https://doi.org/10.1163/9789004328525

Malamuth, N. M. (1986). Predictors of naturalistic sexual aggression. Journal of Personality and Social Psychology, 50(5), 953-962. https://doi.org/10.1037/0022-3514.50.5.953 
Malamuth, N. M. (2018). "Adding fuel to the fire"? Does exposure to non-consenting adult or to child pornography increase risk of sexual aggression? Aggression and Violent Behavior, 41, 74-89. https://doi.org/10.1016/j.avb.2018.02.013

Malamuth, N. M., Addison, T., \& Koss, M. P. (2000). Pornography and sexual aggression: Are there reliable effects and can we understand them? Annual Review of Sex Research, 11, 2691. https://doi.org/10.1080/10532528.2000.10559784

Malamuth, N. M., \& Ceniti, J. (1986). Repeated exposure to violent and nonviolent pornography: Likelihood of raping ratings and laboratory aggression against women. Aggressive Behavior, 12(2), 129-137. https://doi.org/10.1002/1098-2337(1986)12:2<129::AIDAB2480120207>3.0.CO;2-P

Malamuth, N. M., \& Hald, G. M. (2017). The confluence mediational model of sexual aggression. In D. P. Boer, A. R. Beech, \& T. Ward (Eds.), The Wiley handbook on the theories, assessment and treatment of sexual offending (Vol. 1, pp. 53-70). John Wiley \& Sons, Ltd. http://www.tandfonline.com/doi/abs/10.1300/J076v23n03_03

Malamuth, N. M., Hald, G. M., \& Koss, M. P. (2012). Pornography, individual differences in risk and men's acceptance of violence against women in a representative sample. Sex Roles, 66(7-8), 427-439. https://doi.org/10.1007/s11199-011-0082-6

Malamuth, N. M., Linz, D., \& Heavey, C. L. (1995). Using the confluence model of sexual aggression to predict men's conflict with women: A 10-year follow-up study. Journal of Personality and Social Psychology, 69(2), 353-369. https://doi.org/10.1037/00223514.69 .2 .353

Malamuth, N. M., Sockloskie, R. J., Koss, M. P., \& Tanaka, J. S. (1991). Characteristics of aggressors against women: Testing a model using a national sample of college students. 
Journal of Consulting and Clinical Psychology, 59(5), 670-681.

https://doi.org/10.1037/0022-006X.59.5.670

McCoach, D. B., \& Adelson, J. L. (2010). Dealing with dependence (part I): Understanding the effects of clustered data. Gifted Child Quarterly, 54(2), 152-155.

https://doi.org/10.1177/0016986210363076

Petersen, A. C., Crockett, L., Richards, M., \& Boxer, A. (1988). A self-report measure of pubertal status: Reliability, validity, and initial norms. Journal of Youth and Adolescence, 17(2), 117-133. https://doi.org/10.1007/BF01537962

Rasmussen, K. R., Grubbs, J. B., Pargament, K. I., \& Exline, J. J. (2018). Social desirability bias in pornography-related self-reports: The role of religion. Journal of Sex Research, 55(3), 381-394. https://doi.org/10.1080/00224499.2017.1399196

Reynolds, W. M. (1982). Development of reliable and valid short forms of the Marlowe-Crowne Social Desirability Scale. Journal of Clinical Psychology, 38(1), 119-125.

Seto, M. C., Maric, A., \& Barbaree, H. E. (2001). The role of pornography in the etiology of sexual aggression. Aggression and Violent Behavior, 6(1), 35-53. https://doi.org/10.1016/S1359-1789(99)00007-5

Short, M. B., Black, L., Smith, A. H., Wetterneck, C. T., \& Wells, D. E. (2012). A review of Internet pornography use research: Methodology and content from the past 10 years. Cyberpsychology, Behavior, and Social Networking, 15(1), 13-23. https://doi.org/10.1089/cyber.2010.0477

Simpson, J. A., \& Gangestad, S. W. (1991). Individual differences in sociosexuality: Evidence for convergent and discriminant validity. Journal of Personality and Social Psychology, 60(6), 870-883. https://doi.org/10.1037/0022-3514.60.6.870 
Snyder, H. N. (2000). Sexual assault of young children as reported to law enforcement: Victim, incident, and offender characteristics (NCJ No. 182990). Bureau of Justice Statistics. https://www.bjs.gov/content/pub/pdf/saycrle.pdf

Steinberg, L., Sharp, C., Stanford, M. S., \& Tharp, A. T. (2013). New tricks for an old measure: The development of the Barratt Impulsiveness Scale-Brief (BIS-Brief). Psychological Assessment, 25(1), 216-226. https://doi.org/10.1037/a0030550

Stephenson, M. T., Hoyle, R. H., Palmgreen, P., \& Slater, M. D. (2003). Brief measures of sensation seeking for screening and large-scale surveys. Drug and Alcohol Dependence, 72(3), 279-286. https://doi.org/10.1016/j.drugalcdep.2003.08.003

Štulhofer, A., Landripet, I., Matković, T., Koletić, G., Kohut, T., Buško, V., \& Vodopijevec, A. (2020). Are we losing the most relevant cases first? Selective dropout in two independent panels of Croatian adolescents (the PROBIOPS study). Manuscript submitted for publication.

Štulhofer, A., \& Rimac, I. (2009). Determinants of homonegativity in Europe. Journal of Sex Research, 46(1), 24-32. https://doi.org/10.1080/00224490802398373

Szmaragd, C., Clarke, P., \& Steele, F. (2013). Subject specific and population average models for binary longitudinal data: A tutorial. Longitudinal and Life Course Studies, 4(2), 147165. https://doi.org/10.1136/bmj.b2393

Tan, L., \& Grace, R. C. (2008). Social desirability and sexual offenders: A review. Sexual Abuse: A Journal of Research and Treatment, 20(1), 61-87. https://doi.org/10.1177/1079063208314820

Truman, J. L., \& Morgan, R. E. (2018). Criminal victimization, 2015 (NCJ No. 250180). Bureau of Justice Statistics. https://www.bjs.gov/content/pub/pdf/cv15.pdf 
van Buuren, S., \& Groothuis-Oudshoorn, K. (2011). MICE: Multivariate imputation by chained equations in R. Journal Of Statistical Software, 45(3), 1-67. https://doi.org/10.18637/jss.v045.i03

Vega, V., \& Malamuth, N. M. (2007). Predicting sexual aggression: The role of pornography in the context of general and specific risk factors. Aggressive Behaviour, 33, 104-117. https://doi.org/10.1002/ab.20172

Wright, P. J., Tokunaga, R. S., \& Kraus, A. (2016). A meta-analysis of pornography consumption and actual acts of sexual aggression in general population studies. Journal of Communication, 66(1), 183-205. https://doi.org/10.1111/jcom.12201

Ybarra, M. L., Mitchell, K. J., Hamburger, M., Diener-West, M., \& Leaf, P. J. (2011). X-rated material and perpetration of sexually aggressive behavior among children and adolescents: Is there a link? Aggressive Behavior, 37(1), 1-18. https://doi.org/10.1002/ab.20367

Ybarra, M. L., \& Thompson, R. E. (2018). Predicting the emergence of sexual violence in adolescence. Prevention Science, 19(4), 403-415. https://doi.org/10.1007/s11121-017$0810-4$ 


\section{Table 1}

Prevalence of Coital Experience a among Available Cases by Assessment Wave for the Zagreb ( $n=936$ males) and Rijeka Panels $(n=743$ males $)$

\begin{tabular}{|c|c|c|c|c|c|}
\hline & & \multicolumn{2}{|c|}{ Zagreb Panel } & \multicolumn{2}{|c|}{ Rijeka Panel } \\
\hline & & $\%$ & $n$ & $\%$ & $n$ \\
\hline \multicolumn{6}{|l|}{ Wave 1} \\
\hline & Yes & 25.96 & 243 & 25.82 & 134 \\
\hline & No & 74.04 & 693 & 74.18 & 385 \\
\hline \multicolumn{6}{|l|}{ Wave 2} \\
\hline & Yes & 35.61 & 73 & 31.60 & 170 \\
\hline & No & 64.39 & 132 & 68.40 & 368 \\
\hline \multicolumn{6}{|l|}{ Wave 3} \\
\hline & Yes & 37.00 & 84 & 35.25 & 172 \\
\hline & No & 63.00 & 143 & 64.75 & 316 \\
\hline \multicolumn{6}{|l|}{ Wave 4} \\
\hline & Yes & 44.39 & 99 & 40.60 & 188 \\
\hline & No & 55.61 & 124 & 59.40 & 275 \\
\hline \multicolumn{6}{|c|}{ Wave 5} \\
\hline & Yes & 48.10 & 101 & 44.70 & 156 \\
\hline & No & 51.90 & 109 & 55.30 & 193 \\
\hline \multicolumn{6}{|c|}{ Wave 6} \\
\hline & Yes & 54.11 & 79 & 53.12 & 179 \\
\hline & No & 45.89 & 67 & 46.88 & 158 \\
\hline
\end{tabular}

Notes:

${ }^{a}$ Experienced penile-vaginal intercourse at a given assessment wave or any preceding wave 
Table 2

Demographic Information at Study Baseline for the Zagreb $(n=936$ males) and Rijeka Panels $(n=743 \text { males })^{a}$

$\begin{array}{cc}\text { Zagreb } & \text { Rijeka } \\ \text { Panel } & \text { Panel }\end{array}$

$(\%) \quad(\%)$

Age (years)

$\begin{array}{lcc}15 \text { (and under) } & 2.03 & 19.38 \\ 16 & 80.45 & 73.06 \\ 17 \text { (and over) } & 17.52 & 7.56\end{array}$

Living with

Both parents $\quad 77.99 \quad 76.53$

Single parent / other $\quad 22.01 \quad 23.47$

School Type

$\begin{array}{lll}\text { Gymnasium } & 27.24 & 21.53 \\ \text { Other } & 72.76 & 78.47\end{array}$

Gender of Class

Mixed

Males only

24.23

Religious Service Attendance

Less than once a month $\quad 65.71 \quad 76.78$

Once a month or more $\quad 34.29 \quad 23.22$

\begin{tabular}{ccc}
\hline & $M(S D)$ & $M(S D)$ \\
\hline First Year Grade (1-5) & 3.74 & 3.49 \\
& $(0.60)$ & $(0.61)$
\end{tabular}

Notes:

${ }^{\text {a}}$ Estimates for age, family type, and religious services attendance are based on a reduced sample due to school absenteeism and data omissions at study launch. 


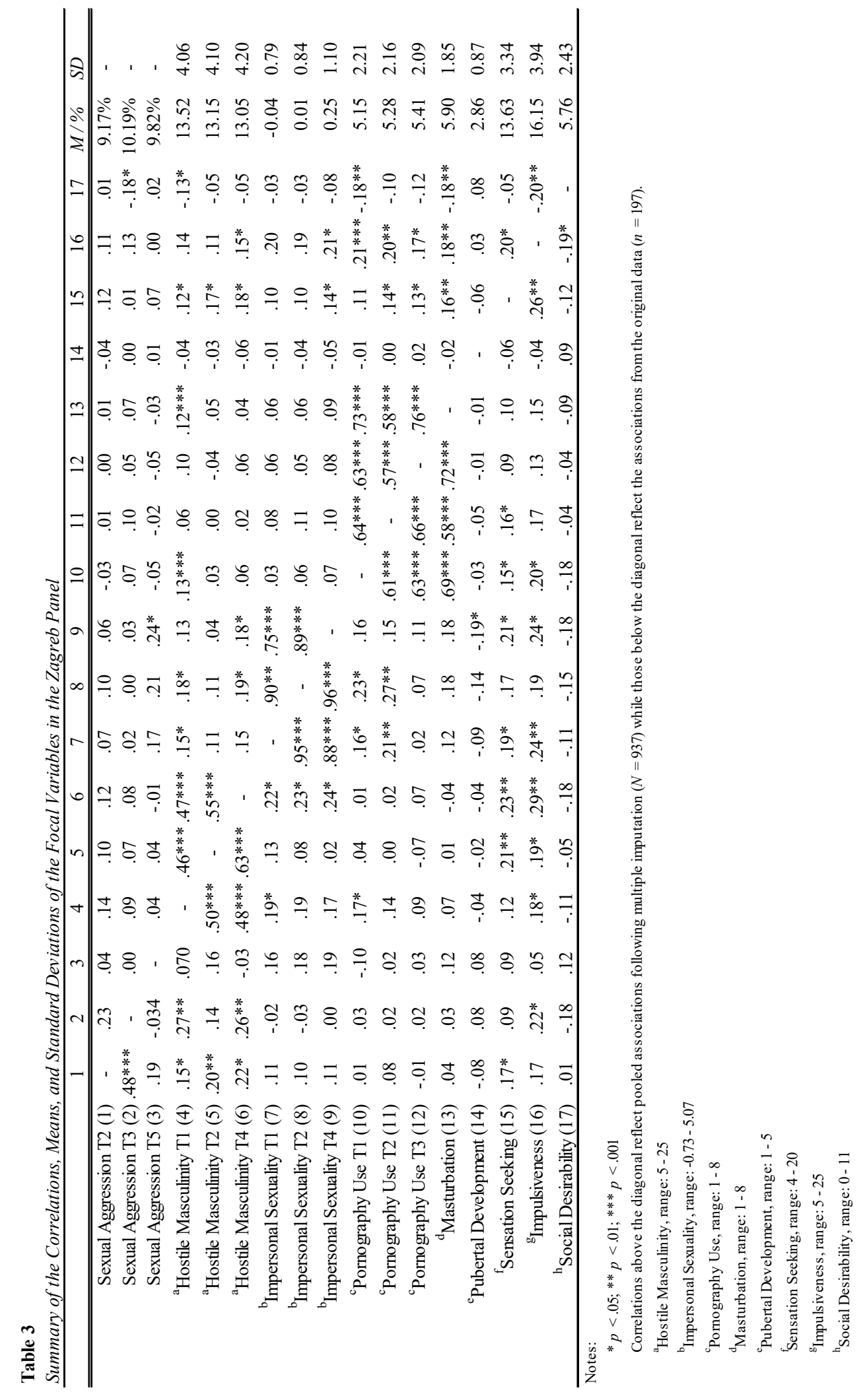




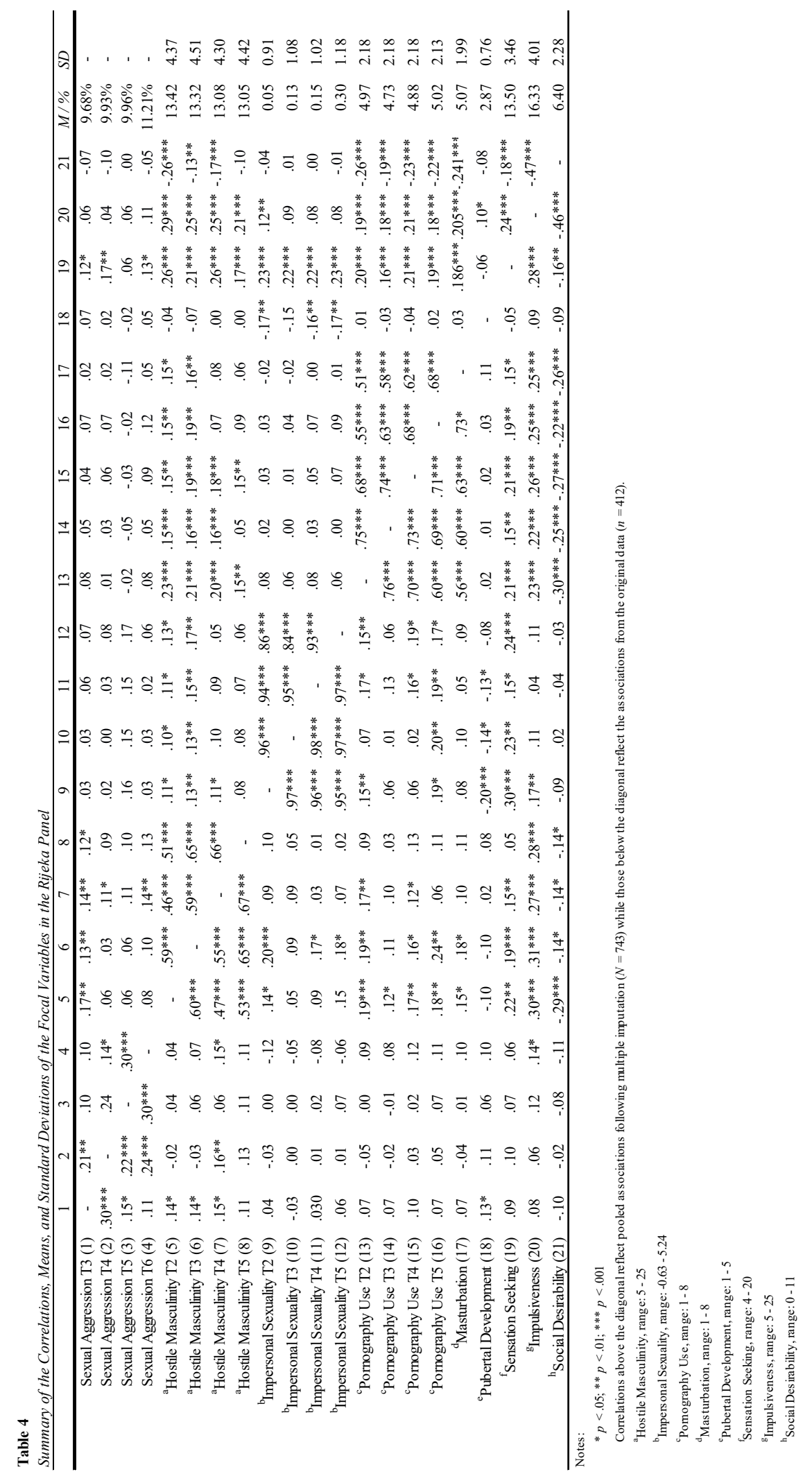


Table 5

Lagged Model 1

\begin{tabular}{lccccc}
\hline & \multicolumn{2}{c}{ Zagreb Panel } & & \multicolumn{2}{c}{ Rijeka Panel } \\
\cline { 2 - 3 } \cline { 5 - 6 } Fixed Effects & $b$ & $p$ & & $b$ & $p$ \\
\hline \hline Intercept & -2.36 & $<.001$ & & -2.53 & $<.001$ \\
Sexual Aggression & 0.22 & .632 & & 1.32 & $<.001$ \\
$\begin{array}{l}\text { Hostile Masculinity } \\
\text { (HM) }\end{array}$ & 0.07 & .589 & & 0.23 & 0.029 \\
$\begin{array}{l}\text { Impersonal Sexuality } \\
\text { (IS) }\end{array}$ & 0.10 & .531 & & 0.09 & 0.396 \\
$\begin{array}{l}\text { Pornography Use } \\
\text { (PU) }\end{array}$ & 0.00 & .982 & & 0.12 & 0.268 \\
HM x IS & -0.02 & .805 & & 0.02 & 0.827 \\
HM x PU & 0.00 & .991 & & -0.02 & 0.802 \\
IS x PU & -0.06 & .592 & & -0.08 & 0.462 \\
HM x IS x PU & 0.02 & .834 & & 0.05 & 0.584 \\
\hline Random Effects & $s^{2}$ & & & & \\
\hline Individual Intercept & 0.17 & - & 0.30 & - \\
\hline \hline
\end{tabular}


Table 6

Lagged Model 2 (with Control Variables)

\begin{tabular}{|c|c|c|c|c|}
\hline \multirow[b]{2}{*}{ Fixed Effects } & \multicolumn{2}{|c|}{ Zagreb Panel } & \multicolumn{2}{|c|}{ Rijeka Panel } \\
\hline & $b$ & $p$ & $b$ & $p$ \\
\hline Intercept & -2.77 & ב.012 & -3.91 & 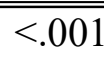 \\
\hline Sexual Aggression & 0.18 & .693 & 1.31 & $<.001$ \\
\hline $\begin{array}{l}\text { Hostile Masculinity } \\
(\mathrm{HM})\end{array}$ & 0.05 & .660 & 0.17 & .115 \\
\hline $\begin{array}{l}\text { Impersonal Sexuality } \\
\text { (IS) }\end{array}$ & 0.09 & .541 & 0.05 & .652 \\
\hline $\begin{array}{l}\text { Pornography Use } \\
\text { (PU) }\end{array}$ & -0.03 & .842 & 0.18 & .211 \\
\hline Pubertal Status & 0.02 & .857 & 0.19 & .262 \\
\hline Masturbation & 0.00 & .973 & -0.11 & .112 \\
\hline Sensation Seeking & 0.02 & .627 & 0.09 & .005 \\
\hline Impulsiveness & 0.02 & .612 & 0.02 & .552 \\
\hline Social Desirability & -0.03 & .632 & -0.02 & .727 \\
\hline HM x IS & -0.02 & .842 & 0.02 & .862 \\
\hline $\mathrm{HM} \times \mathrm{PU}$ & 0.00 & .987 & 0.00 & .985 \\
\hline IS $x$ PU & -0.06 & .596 & -0.06 & .550 \\
\hline HM x IS x PU & 0.02 & .841 & 0.05 & .604 \\
\hline Random Effects & $s^{2}$ & & $s^{2}$ & \\
\hline Individual Intercept & 0.14 & - & 0.21 & - \\
\hline
\end{tabular}


Table 7

Contemporaneous Model

\begin{tabular}{|c|c|c|c|c|}
\hline \multirow[b]{2}{*}{ Fixed Effects } & \multicolumn{2}{|c|}{ Zagreb Panel } & \multicolumn{2}{|c|}{ Rijeka Panel } \\
\hline & $b$ & $p$ & $b$ & $p$ \\
\hline Intercept & -2.94 & $<<.001$ & -2.28 & $<+.001$ \\
\hline $\begin{array}{l}\text { Hostile Masculinity } \\
\text { (HM) }\end{array}$ & 0.28 & .038 & 0.36 & $<.001$ \\
\hline $\begin{array}{l}\text { Impersonal Sexuality } \\
\text { (IS) }\end{array}$ & 0.16 & .533 & 0.08 & .417 \\
\hline $\begin{array}{l}\text { Pornography Use } \\
\text { (PU) }\end{array}$ & 0.23 & .194 & 0.13 & .217 \\
\hline HM x IS & 0.05 & .751 & -0.01 & .937 \\
\hline $\mathrm{HM}$ x PU & 0.03 & .820 & 0.02 & .845 \\
\hline IS $x$ PU & 0.02 & .856 & -0.04 & .702 \\
\hline HM x IS x PU & -0.05 & .692 & -0.04 & .625 \\
\hline Random Effects & $s^{2}$ & & $s^{2}$ & \\
\hline Individual Intercept & 1.98 & - & 1.02 & - \\
\hline
\end{tabular}




\section{Figure 1}

Illustrations of the Impact of Missing Data on Long-Form Data for Lagged Analyses

Wide-Form Data

Participant T1 Aggression T2 Aggression T3 Aggression T4 Aggression T5 Aggression T6 Aggression

\begin{tabular}{|c|c|c|c|c|c|c|}
\hline Participant & T1 Aggression T2 Aggression T3 Aggression T4 Aggression T5 Aggression T6 Aggression \\
\hline A & 0 & 0 & 1 & 0 & 1 & 0 \\
\hline B & 1 & 0 & MISSING & 1 & 0 & 0 \\
\hline
\end{tabular}

Long-Form Data

\begin{tabular}{|c|c|c|c|}
\multicolumn{1}{c}{ Participant } & \multicolumn{1}{c}{ Time } & \multicolumn{1}{c|}{ Aggression $(\boldsymbol{t})$} & Aggression $(t+1)$ \\
\hline A & 1 & 0 & 0 \\
\hline A & 2 & 0 & 1 \\
\hline A & 3 & 1 & 0 \\
\hline A & 4 & 0 & 1 \\
\hline A & 5 & 1 & 0 \\
\hline A & 6 & 0 & - \\
\hline B & 1 & 1 & 0 \\
\hline B & 2 & 0 & MISSING \\
\hline B & 3 & MISSING & 1 \\
\hline B & 4 & 1 & 0 \\
\hline B & 5 & 0 & 0 \\
\hline B & 6 & 0 & - \\
\hline
\end{tabular}

Note. Illustration of how a single missing observation on sexual aggression results in two missing values in long-form lagged datasets. 